\title{
Rationale, design, and baseline characteristics of the Acetylcystein for Contrast-Induced nephropaThy (ACT) Trial: a pragmatic randomized controlled trial to evaluate the efficacy of acetylcysteine for the prevention of contrast-induced nephropathy
} The ACT Trial Investigators

Address: Research Institute - Hospital do Coracao (HCor), Rua Abilio Soares 250, 12 floor, 04005-000 - São Paulo - SP, Brazil Email: The ACT Trial Investigators - oberwanger@hcor.com.br

Published: 4 June 2009

Trials 2009, 10:38 doi:10.1186/1745-62/5-10-38
Received: 16 January 2009

Accepted: 4 June 2009

This article is available from: http://www.trialsjournal.com/content//0/1/38

(c) 2009 The ACT Trial Investigators; licensee BioMed Central Ltd.

This is an Open Access article distributed under the terms of the Creative Commons Attribution License (http://creativecommons.org/licenses/by/2.0), which permits unrestricted use, distribution, and reproduction in any medium, provided the original work is properly cited.

\begin{abstract}
Background: Aceltylcysteine has been evaluated in several small trials as a means of reducing the risk of contrast-induced nephropathy (CIN), however systematic reviews of these studies do not provide conclusive answers. Therefore, a large randomized controlled trial (RCT) is needed to provide a reliable answer as to whether acetylcysteine is effective in decreasing the risk of $\mathrm{CIN}$ in high-risk patients undergoing angiographic procedures.
\end{abstract}

Methods: ACT is a RCT of acetylcysteine versus placebo in 2,300 patients at-risk for CIN undergoing an intravascular angiographic procedure. The randomization list will be concealed. Participants, health care staff, investigators and outcome assessors will be blinded to whether patients receive acetylcysteine or placebo. All analysis will follow the intention-to-treat principle. The study drugs (acetylcysteine $1200 \mathrm{mg}$ or placebo) will be administered orally twice daily for two doses before and two doses after the procedure. The primary outcome is the occurrence of CIN, defined as a $25 \%$ elevation of serum creatinine above baseline between 48 and 96 hours after angiography.

Discussion: The first patient entered the trial on September, 2008. Up to April 7, 2009, 810 patients had been included in 35 centers. The mean age was 69 (Standard deviation: 10), 18\% had a baseline serum creatinine $>1.5 \mathrm{mg} / \mathrm{dL}, 57 \%$ were diabetics and $13 \%$ had a history of heart failure. The ongoing ACT Trial is the largest multicentre RCT that will determine whether acetylcysteine is effective in decreasing the risk of $\mathrm{CIN}$ in patients at risk undergoing angiography.

Trial registration: Clinicaltrials.gov NCT00736866

\section{Background}

Contrast-induced nephropathy (CIN) is a potentially serious complication of diagnostic and therapeutic procedures requiring intravenous administration of radiocontrast media. CIN is the third most common cause of new acute renal failure in hospitalized patients and is associated with the need of dialysis, prolonged hospital stay, increased health care costs and death $[1,2]$

The incidence of a rise in the serum creatinine of more than $50 \%$ above baseline or of more than $1 \mathrm{mg} / \mathrm{dL}$ is negligible in patients with normal renal function[3] How- 
ever, patients with previous risk factors such as preexisting renal failure, diabetes, congestive heart failure, advanced age or concurrent administration of nephrotoxic drugs are at a much increased risk. [4] The incidence of CIN has been reported as 9 to $38 \%$ in patients with mild to moderate renal insufficiency and diabetes mellitus. [3,5] Patients requiring coronary intervention are another group at increased risk, with an overall incidence of acute renal failure (defined as a $25 \%$ increase in serum creatinine above baseline) of $14.4 \%$. [2]

Optimal care to prevent CIN remains uncertain. [6] Patients with normal renal function and no other risk factors are at little risk and few measures are needed except for avoidance of volume depletion. For patients at increased risk the most well established measures are: 1) Avoidance of high osmolal agents[7]; 2) Avoidance of larger radiocontrast doses and repetitive studies (less than 48 hours apart); 3) Volume expansion with isotonic fluids[8] The infusion of isotonic sodium bicarbonate has been shown to be superior to isotonic saline to prevent CIN in most, but not all, randomized controlled trials. [912]

The role of acetylcysteine in preventing CIN has been evaluated in several randomized controlled trials and systematic reviews, being the most widely studied of all prophylaxis strategies. [13-16] Previous trials have low statistical power (median study size was 80 patients) and most failed to met quality standards such as allocation concealment, blinding, and intention-to-treat analysis. Similarly, systematic reviews and meta-analysis have found conflicting results. The most recent review, published by Kelly et al., included 26 randomized trials and found a protective effect of acetylcysteine (relative risk reduction of $38 \%$ ), but with significant heterogeneity between the included trials ( $\mathrm{I}^{2}$ of $\left.55 \%\right)$, meaning that $55 \%$ of the heterogeneity found could not be explained by chance alone. [16] This quite significant heterogeneity among studies' results prevents definitive conclusions to be drawn. An attempt to reveal the causes of heterogeneity using unsupervised clustering analysis revealed that a few smaller trials of average lower quality had similar very favorable results. [15] Removing these studies would leave another cluster of homogeneous trials with adequate quality showing neutral effect of acetylcysteine for preventing CIN. Besides methodological quality, differences in contrast media, outcome definitions, patient selection, dose and route of administration of acetylcysteine, and co-interventions may have contributed to the observed heterogeneity between trials.

Thus, the available evidence on the effects of acetylcysteine does not allow definitive conclusions about the efficacy of acetylcysteine for prevention of CIN. Moreover, it is not clear from previous evidence, what is the most effective dose of acetylcysteine, and what population benefits most from this intervention. A large randomized controlled trial, with high methodologic quality, involving several centers and with sufficient power to evaluate clinically relevant outcomes is needed to ultimately resolve whether acetylcysteine prevents CIN.

The ACT Trial is a randomized controlled trial to determine whether acetylcyteine reduces the risk for CIN in 2300 at-risk patients (ie, with previous renal failure or with other risk factors for contrast-induced nephropathy) undergoing an intravascular angiographic procedure. CIN is defined as an increase of $25 \%$ in serum creatinine measured between 48 to 96 hours compared to baseline. The ACT represents the largest trial conducted so far in this field.

\section{Methods \\ Study Design}

ACT is a randomized (concealed) controlled trial of acetylcysteine versus placebo in patients at-risk for CIN undergoing an intravascular angiographic procedure. Participants, health care staff, data collectors, outcome assessors, and statisticians will be blinded to whether patients receive acetylcysteine or placebo. All analysis will follow the intention-to-treat principle.

\section{Eligibility}

The study population is comprised of patients at increased risk for CIN undergoing an angiographic procedure (coronary or peripheral arterial diagnostic intravascular angiography or percutaneous intervention). Therefore, risk factors for CIN such as previous renal failure, diabetes mellitus, heart failure, shock states and age greater than 70 years old were selected as the ACT study's inclusion criteria. [6] The Appendix presents the ACT trial's inclusion and exclusion criteria.

\section{Randomization and Allocation Concealment}

Patients are randomized after providing a written informed consent in a 1:1 ratio to receive acetylcysteine or matching placebo. The random allocation list was generated in random permuted blocks of variable size $(4,6,8$ or 10) and was stratified by investigator centre. In order to guarantee concealment of the allocation list, randomization is implemented through a 24 -hour web-based automated randomization system, making the sequence allocation totally unpredictable for the professionals responsible for entering the patients in the trial in each centre. The randomization list was generated and implemented by the The ACT study Clinical Data Management System (CDMS), a web based system that has been developed on a Microsoft SQL ${ }^{\circledR}$ platform by a team of programmers of the Research Institute - Hcor, Sao Paulo, Brazil. 


\section{Interventions}

\section{Study Drugs}

The study drugs (acetylcysteine 1200 mg or matching placebo) will be administered orally twice daily for two doses before the procedure and two doses after the procedure (Figure 1). On occasion, when the patient is included in the study on the same day of the angiography, the pragmatic design of the ACT trial allows one dose to be administered at least 6 hours before the procedure and three doses after it.

\section{Cointerventions}

Hydration with $0.9 \%$ saline, $1 \mathrm{~mL} / \mathrm{kg} /$ hour, starting 6-12 hours before angiography and continued for 6-12 hours after is strongly recommended for all patients. Changes in the total volume or flow may be needed according to attending physician, for example, for patients with signs of congestive heart failure.

All other decisions about management of patients are at the discretion of the responsible doctor, except that non-trial acetylcysteine will not be allowed during the trial period.

\section{Blinding}

All study participants will be blinded to the assigned treatment, including patients, healthcare personnel, investigators and outcome assessors. The study statistician will be the only person able to access unblinded data, albeit she will not have any contact with participants and will not to carry any analysis according to study group before the database is locked.

The study drug, acetylcysteine or placebo, are packed in identical envelops. The envelop label contains information about the study drug and the treatment number. Each envelop contains $600 \mathrm{mg}$ of oral powder acetylcisteine or placebo to be diluted in water. The powder and the solution in water are identical in appearance, taste and smell. In this regard, both are orange flavored.

\section{Outcomes}

All outcomes of interest will be assessed in a blinded fashion. Data will be obtained at baseline, 48-96 hours and 30 days. The primary outcome of the ACT Trial is the occurrence of contrast-induced nephropathy (CIN), defined as a $25 \%$ elevation of serum creatinine above baseline between 48 and 96 hours after angiography. The secondary outcomes are: (1) A composite outcome of death, need of dialysis or a doubling in serum creatinine in thirty days; (2) A composite of death or need of dialysis in thirty days; (3) Individual components of the composite outcome.

\section{Data Collection and Management}

\section{Baseline Dato}

The following data will be recorded at the baseline visit:

- Patient's initials, gender, date of birth;

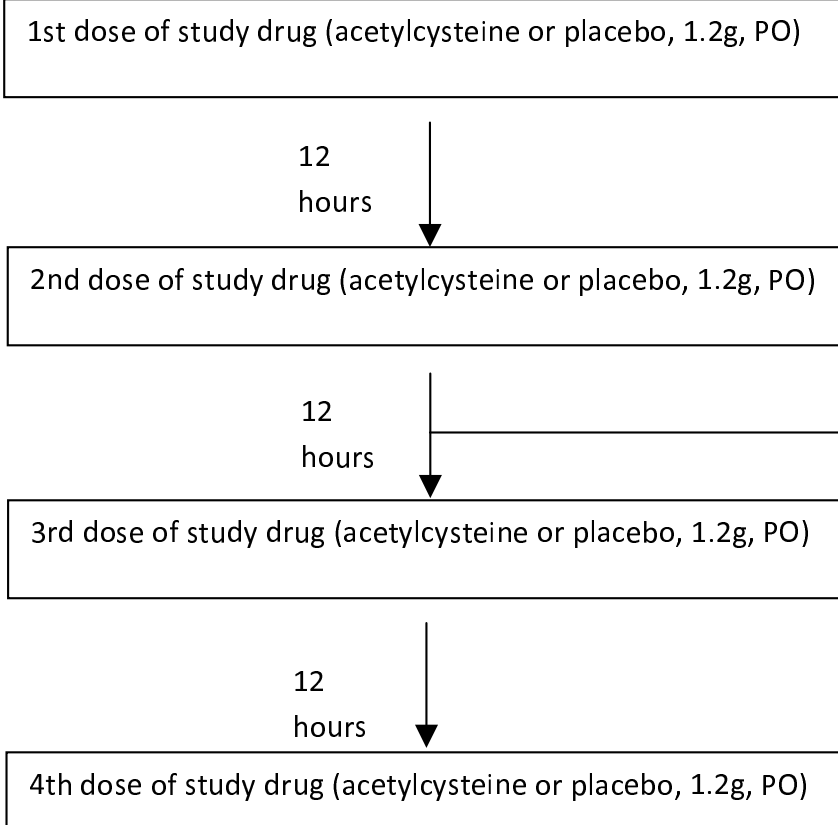

\section{Figure I}

Flowchart of study drug administration. Angiography may be done at any time between 6 hours after the first study drug dose to just before the $3^{\text {rd }}$ study drug dose. 
- Inclusion and exclusion criteria;

- Relevant medical history: hypertension; use of nonsteroidal anti-inflammatory within last 7 days; use of angiotensin converting enzyme inhibitors, diuretics, metformin; use of aminoglycosides, vancomycin, and other antibiotics;

- Serum creatinine: The most recent serum creatinine measured within the last three months will be recorded. When a recent creatinine measure is not available, a blood sample measurement will be drawn before angiography;

- Physical exam: arterial blood pressure and weight;

-Whether the patient undergone an angiographic procedure in the last 72 hours; if yes, the purpose (diagnosis or treatment), and whether any measure to prevent CIN was provided.

\section{Treatment Data}

The following data regarding treatment will be obtained:

- Administration of the first and second study drug doses; with details regarding timing and amount per dose;

- Hydration scheme before angiographic procedure: type of solution, total volume and duration of infusion;

- Angiographic procedure: date, hour and type (coronary or peripheral; diagnostic or therapeutic; if therapeutic, angioplasty, bare metal stent, drug-eluted stent or a combination of them;

- Contrast: type, volume administered;

- Whether the procedure was indicated for a patient with acute coronary syndrome.

\section{Short-Term Follow-up Data}

This is the main follow-up visit. Patients will have a serum creatinine measured between 48 and 96 hours after angiography for evaluation of the study primary outcome. Other data elements which will be recorded are:

- Administration of the third and fourth study drug doses; with details regarding timing and amount per dose;

- Hydration scheme after angiographic procedure: type of solution, total volume and duration of infusion;
- Whether the patient undergone an angiographic procedure within 72 hours after the index angiography; if yes, date, type, and measures to prevent CIN;

- Vital status; in case of deaths, date and cause;

- Need of dialysis.

One month follow-up data

Research personnel will contact patients 30 days after the angiographic procedure and record the occurrence of:

- Angiographic procedure: date, type, measures to prevent CIN;

- Vital status; in case of deaths, date and cause;

- Need of dialysis.

Adverse events form

This form contains questions for adverse events which may occasionally occur after acetylcysteine (nausea, emesis, urticaria, bronchospasm), open questions for registration of any other adverse event, and a question for severe adverse event with a field for detailing the event.

\section{Clinical Data Management System (CDMS) and Quality Control}

The ACT study CDMS is a web based system that has been developed on a Microsoft SQL ${ }^{\oplus}$ platform by a team of programmers of the Research Institute - HCor. Its functionalities include: patient registration, 24-hour concealed randomization, data entry, data cleaning and exportation for analysis.

The CDMS also provides reports on the status of the study forms (completed forms, overdue forms), weekly study recruitment by center and graphs of observed and expected cumulative recruitment.

\section{Sample size}

Based on a recent systematic review and meta-analysis of 26 randomized controlled trials, we anticipate an incidence of CIN at 48 to 96 hours of approximately 15\%[16] In order to detect a $30 \%$ relative risk reduction (RRR), with $90 \%$ statistical power, and a two-tailed alpha of $5 \%$, we will need to include at least 2,300 patients.

\section{Statistical Analysis Plan}

All analysis will follow the intention-to-treat principle. The effect of acetylcysteine versus placebo on the primary endpoint, incidence of CIN between 48 to 96 hours, will be evaluated with a chi-square test. The magnitude of association will be presented as a risk ratio, with 95\% confidence interval and number needed to treat (NNT). Sta- 
tistical significance will be inferred using a significance level of 0.05 .

Secondary outcomes evaluated 30 days after randomization will be presented as Kaplan-Meier curves according to the assigned treatment, and tested with the log-rank method. Hazard ratios and 95\% confidence intervals will be calculated using non-adjusted Cox proportional hazards.

The incidence of the primary outcome will be analyzed in pre-specified subgroups using risk ratios and $95 \%$ confidence intervals. A subgroup effect will be inferred when the chi-squared test for homogeneity of effects is statistically significant. The following subgroups will be analyzed: 1) $\leq 70$ year-old versus $>70$ year-old; 2) Male vs. female; 3 ) No previous renal failure vs. previous renal failure (serum creatinine $>1.5 \mathrm{mg} / \mathrm{dL}$ ); 4 ) Not diabetic vs diabetic; 5) Amount of contrast agent $<140 \mathrm{~mL} v \mathrm{ss} . \geq 140 \mathrm{~mL}$. [17]

In the main trial publication, we also plan to include a random effects (DerSimonian-Laird) meta-analysis to combine ACT's results with those of previous randomized controlled trials evaluating acetylcysteine versus placebo for prevention of contrast-induced nephropathy. [18]

\section{Ethical Aspects}

Each study site will submit the study protocol to its institutional Research Ethics Board (REB). The study should start only after being approved by the REB. Written informed consent will be obtained from all participants. This study is in compliance with the Helsinki Declaration.

\section{Trial Organization and Management}

\section{Trial Management Team (TMT)}

A team based on the Research Institute -Hcor, São Paulo, Brazil, will manage the trial on a day-to-day basis. The TMT is comprised by the chief investigator, a project manager, a clinical research associate, a statistician and four computer programmers. Data management is assumed by both the medical project manager and the clinical research associate.

The responsibilities of the TMT include:

- Selecting and training participant centers;

- Assisting trial centers with regulatory submissions;

- Distributing and supplying study sites with the study drug and forms;

- Monitoring recruitment and follow-up at participant centers;
- Data management: Elaboration, testing and maintenance of the electronic data capture system; data quality control;

- Data analysis;

- Servicing the Trial Steering Committee.

\section{Trial Steering Committee (TSC)}

The TSC is responsible for providing overall supervision of the trial, assist with development of the study protocol and preparing the final manuscript. All other trial's committees report to the TSC. The TSC members are epidemiologists, with in-dept training in designing and conducting randomized controlled trials, or cardiologists experienced in the conduction of multicentre clinical trials.

\section{Trial Centers}

Fifty four invasive catheterization centers in Brazil are participating in the study. Details of the participating centers are given in the Appendix.

\section{Publication policy}

The ACT study success depends on all its collaborators. Therefore, the primary results of the trial will be published under the name of ACT Trial Investigators. The contributions of all collaborators, their names and respective institutions, not only the members from TSC or TMT, will be acknowledged in the manuscript. To safeguard the scientific integrity of the study, data from this study will be submitted to publication only after the final approval from the TSC.

\section{Data Monitoring Committee}

The ACT Study does not have a Data Monitoring Committee, nor will we conduct interim analysis to evaluate drug

Table I: Baseline demographic and clinical characteristics

\begin{tabular}{|c|c|}
\hline Characteristic & $\begin{array}{c}\text { Total } \\
(N=810)\end{array}$ \\
\hline Female sex - no. (\%) & $305(38)$ \\
\hline \multicolumn{2}{|l|}{ Age - years } \\
\hline Mean (SD) & $69(10)$ \\
\hline \multicolumn{2}{|c|}{ Patients fulfilling inclusion criteria - no. (\%) } \\
\hline Recent creatinine $>1.5 \mathrm{mg} / \mathrm{dL}$ & $148(18)$ \\
\hline Diabetes mellitus & $458(57)$ \\
\hline Heart failure & $105(13)$ \\
\hline Shock & $2(0.2)$ \\
\hline Aged $>70$ years & $458(57)$ \\
\hline History of hypertension - no. (\%) & $659(81.4)$ \\
\hline \multicolumn{2}{|l|}{ Serum creatinine $-\mathrm{mg} / \mathrm{dL}$} \\
\hline Median (IQR) & I.I (0.5) \\
\hline \multicolumn{2}{|c|}{ Estimated creatinine clearance $*-\mathrm{mL} / \mathrm{kg} / \mathrm{min}$} \\
\hline Median (IQR) & $60(38)$ \\
\hline
\end{tabular}

$\mathrm{SD}$, standard deviation; IQR, interquartile range.

* Creatinine clearance estimated by the Cockcroft-Gault formula. 
efficacy or safety. The arguments supporting this decision are: 1) Oral acetylcysteine has a very good safety profile, being tested in several small clinical trials and used in practice for a long period of time. Adverse reactions (specially unexpected severe adverse events) and drug interactions are uncommon and rarely severe. [19] Therefore, early stopping for safety reasons would be highly unlikely. 2) Trials stopped early for benefit usually reach large and non-plausible treatment effects (relative risk reductions greater than $50 \%$ ) due to low numbers of events and thus low statistical power to reach robust results. In consequence, several experts in the field of clinical trials have criticized and discouraged such an approach. [20] 3) The study has limited power to evaluate clinical events such as need of dialysis or death. We expect an incidence of need of dialysis or death in 30 days between $2 \%$ and $3 \%$. A study enrolling 7,650 patients would be needed to have $80 \%$ power to show a reduction in this combined outcome from $3 \%$ to $2 \%$. Therefore, it is very unlikely that evidence of benefit beyond doubt on clinical outcomes would be found in an interim analysis.

\section{Discussion}

Contrast-induced nephropathy is a common complication after coronary or peripheral angiography. Patients at increased risk include those with previous renal failure, diabetes mellitus, heart failure, shock states and elderly. [4] Acetylcystine represents a simple, non-toxic, low-cost, and wide available intervention. The majority of previous trials that tested this intervention had small sample sizes, inadequate methodology, have reached conflicting results, and have not assessed patient-important outcomes. At present there is limited evidence that acetylcysteine together with hydration may be useful as standard prophylactic procedure in patients at high risk for CIN. Therefore, a well designed trial with adequate statistical power is needed to resolve the question of acetylcysteine for the prevention of CIN.

ACT investigators started recruitment on September, 15, 2008. To date (April 7, 2009), 35 centers started recruitment and 810 patients have been randomized. Thus, ACT is already the largest randomized controlled trial evaluating a strategy to prevent CIN[16] Patients' baseline characteristics are depicted in table 1 . Mean age was 69 (standard deviation 10), with $57 \%$ being older than 70 years. Prevalence of renal failure (as defined by a baseline serum creatinine $>1.5 \mathrm{mg} / \mathrm{dL}$ ) was $18 \%$, of diabetes was $57 \%$ and of heart failure was $13 \%$.

The ACT study was planned to be the largest, doubleblind, randomized controlled trial, comparing acetylcysteine to placebo in high risk patients undergoing peripheral or cardiac invasive angiography conducted to date. The results of ACT will convey a reliable and precise estimate of acetylcysteine's effectiveness on preventing CIN in such population. Regardless of the results, the ACT trial will have important implications for clinical practice. If the ACT trial demonstrates no effect on contrast induced nephropathy and on other patient-important outcomes, then it will allow physicians to avoid unnecessary patient risk and decrease costs. On the other hand, if the ACT Trial demonstrates a beneficial effect of acetylcysteine, then it will have clinical impact on preventing renal adverse events in high risk patients undergoing angiographic procedures.

\section{Competing interests}

The authors declare that they have no competing interests.

\section{Authors' contributions}

The ACT Trial Investigators contributions are listed in the Acknowledgements. All the investigators at study sites participated in the planning phase of the study, besides their contributions in enrolling and following patients. The Writing Committee elaborated the article and assumes full responsibility for its overall content and integrity.

\section{Appendix}

\section{Eligibility criteria of the ACT Trial}

Inclusion criteria

Patients undergoing an angiographic procedure must meet at least one of the following criteria to be included:

- Age > 70 years;

- Renal failure (defined as a serum creatinine higher than $1.5 \mathrm{mg} / \mathrm{dL}$ within the last 3 months);

- Diabetes mellitus;

- Congestive heart failure or left ventricular ejection fraction $<0.45$;

- Shock;

- Intra-aortic balloon counterpulsation.

\section{Exclusion criteria}

Patients are excluded if they met any of the following criteria:

- Pregnant or breastfeeding women, or aged below 45 years and with no efficacious contraceptive method;

- Patients on dialysis;

- Previous enrollment in ACT study;

- Patient did not provide informed consent; 
- Patients with ST segment elevation myocardial infarction unable to receive the study hydration protocol.

\section{Acknowledgements}

The management activities of the trial are funded by the Research Institute/ Hospital do Coração (São Paulo, SP, Brazil). Trial work in the sites is being conducted without financial reimbursement. Medley Indústria Farmacêutica S/A (Campinas, SP, Brazil), a pharmaceutical company, packed and donated the acetylcysteine and the placebo. Medley will not have any other participation in the study.

\section{The ACT Trial Investigators consists of:}

Trial Steering Committee

Otávio Berwanger (chair), Amanda G.M.R. Sousa, José Eduardo Sousa, Alexandre B. Cavalcanti, Celso Amodeo, Leda D. Lotaif.

Writing Committee

Otávio Berwanger, Amanda G.M.R. Sousa, Alexandre B. Cavalcanti, Anna M. Buehler, Mariana T. Carballo, José Eduardo Sousa.

Trial Management Team

Otávio Berwanger (chief investigator), Alexandre B. Cavalcanti (project manager), Anna M. Buehler (project manager), Mariana T. Carballo (statistician), Carlos E. S. Cardoso (data management), Alessandra A. Kodama (data management), Dalmo da Silva (data management), Adailton L. Mendes (senior computer programmer), José Lobato (chief computer programmer).

\section{Investigators}

Universidade Federal do Pará, Belém, PA: Eduardo Costa (Principal Investigator - PI). Fundação Pública Estadual Hospital de Clínicas Gaspar Viana, Belém, PA: Hélder Reis (PI), Gabriela M. C. C. de Assis, Gracilene L. Cardoso. Hospital UDI, São Luís, MA: Márcio M. Barbosa (PI), Francisco A. A. de Aguiar Filho, Carlos A. V. Gama. Hospital Santa Izabel, Salvador, BA: Marcelo Góes A. Silva, Bruno M. Aguiar, Marcelo G. Ferreira, Gilson S. Feitosa. Hospital das Clínicas - Universidade Federal de Pernambuco, Recife, PE: Edgard Victor Filho (PI), Emmanuel B. D. Rocha. Natal Hospital Center, Natal, RN: Maria S. M. O. Paiva (PI), Eliana R. Czochra. INCOR - HEMOCÁRDIO, Natal, RN: Ludmila A. R. R. Oliveira (PI), Itamar R. de Oliveira, Flávia Pinheiro. Santa Casa de Maceió, Maceió, AL: Gilvan O. Dourado (PI), Antônio L. Luna Filho, Amilson Pacheco. Hospital de Terapia Intensiva, Teresina, PI: Paulo M. S. Nunes (PI), Alcino P. de Sá Filho. Cardiocenter - Hospital Santa Paula, João Pessoa, PB: Helman C. Martins (PI), Marcelo A. C. Lopes, Marco A. V. Barros. Hospital Barra D'Or, Rio de Janeiro, RJ: Cláudia Mattos (PI), Miguel A. Neves, Cesar Rocha Medeiros. Hospital

Copa D'Or, Rio de Janeiro, RJ: Cláudia Mattos (PI), Leonardo Duarte. Hospital Quinta D'Or, Rio de Janeiro, RJ: Cláudia Mattos (PI). Instituto Nacional de Cardiologia Laranjeiras, Rio de Janeiro, RJ: Helena Cramer (PI), Bráulio Santos Jr., Bernardo R. Tura. Hospital São Vicente de Paulo, Rio de Janeiro, RJ: Cyro V. Rodrigues (PI), Luis A. O. Terreiro, Mônica A. Alves. Hospital Escola Álvaro Alvim, Campos, RJ: Jamil S. Soares (PI), Cristiane C. da Cunha. Hospital São José do Avaí, Itaperuna, RJ: Antônio C. B. da Silva (PI), Alexandre M. Barcelos, Marco A. Teixeira, Joselena S. Pinto. Hospital Felício Rocho, Belo Horizonte, MG: Jamil A. Saad (PI), Ari Mandil, Eduardo Falcheto. Hospital Universitário São José, Belo Horizonte, MG: Carlos Augusto F.
Arêas (PI), Frederico T. C. Dall'Orto, Ivan F. Freitas. Instituto do Coração do Triângulo Mineiro, Uberlândia, MG: Roberto V. Botelho (PI), Míriam D. G. Seabra, César A. S. Rosa, Antônio D. S. Pereira, Samir S. A. Reis, Vilmar J. Pereira, Silvia M. C. Cunha. Instituto de Clínicas e Cirurgia de Juiz de Fora - Hospital Monte Sinai, Juiz de Fora, MG: Gustavo M. Ramalho (PI), Renata R. dos Santos. Hospital do Coração de Juiz de Fora, Juiz de Fora, MG: Antônio J. Muniz (PI), João B. L. Loures, Thaís Amorim. Santa Casa de Juiz de Fora, Juiz de Fora, MG: Antônio J. Muniz (PI), João B. L. Loures, Ana Cristina O. Abraão. Instituto Uberabense de Cardiologia Invasiva, Uberaba, MG: Rone M. Padilha (PI). Hospital do Coração, São Paulo, SP: José E. Sousa (TST, PI), Amanda G. M. R. Sousa (TST, PI), Adriana C. Moreira. Instituto Dante Pazzanese de Cardiologia, São Paulo, SP: Amanda G. M. R. Sousa (TST, PI), Fausto Feres (PI), Marinella Centemero, Ribamar Costa, Vinícius Esteves. Hospital Santa Marcelina, São Paulo, SP: Breno O. Almeida (PI), Bruno L. Janella, Mariana C. Almeida. Hospital Samaritano, São Paulo, SP: Francisco P. Stella (PI), José D. Almeida, Vivian R. Kloth. Cardiologia Intervencionista - Hospital Beneficência Portuguesa, São Paulo, SP: José Armando Mangione (PI), Maria F. Z. Mauro. Hospital Stella Maris, São Paulo, SP: Fernando Tallo (PI), Diogo José A. Santos. Hospital Bandeirantes, São Paulo, SP: Hélio Castello (PI), Marcelo J. C. Cantarelli, Sandra Baradel. Santa Casa de São Paulo, São Paulo, SP: Francisco P. Stella (PI), Marcos O. das Candeias, Vivian R. Kloth. Hospital Santa Lucinda - Hemocordis, Sorocaba, SP: José R. Maiello (PI), Emerson A. Seixas. Santa Casa de Limeira, Limeira, SP: Pablo T. Teixerense (PI), João F. B. de Toledo, Luiz A. Gubolino. Associação Hospital de Bauru, Bauru, SP: Guilherme J. G. Prates (PI), Hugo Yokoyama, Plínio de Almeida, Caio M. A. Pessoa. Instituto de Moléstias Cardiovasculares - IMC, São José do Rio Preto, SP: Nilton C. S. Machado (PI), Pedro G. A. Garzon, André F. P. Antonângelo, Paula B. S. Galeazzi, Clotildes S. P. Queirantes, Vitor H. Cavalini. Santa Casa de Marília, Marília, SP: André Labrunie (PI), Pedro B. de Andrade, Marden A. Tebet. Serviço de Cardiologia de Catanduva, Catanduva, SP: Fernando S. Devito (coPI), Carlos E. Farias (co-PI). Centro de Hemodinâmica de Piracicaba, Piracicaba, SP: Eduardo L. Nicolela Jr. (PI), Humberto M. Passos, Priscila Rubio. Incorpi - Hospital Fornecedores de Cana, Piracicaba, SP: Luiz A. Gubolino (PI), Pablo T. Teixerense (PI), João F. B. de Toledo. Santa Casa de Porto Alegre, Porto Alegre, RS: Gilberto L. Nunes (PI), Cíntia Roehrig, Alessandra T. de Oliveira. Hospital Moinhos de Vento, Porto Alegre, RS: Marco V. Wainstein (PI), Jorge P. Ribeiro, Cátia Teixeira. Prócardíaco, Pelotas, RS: Taufik N. Atallah, Carlos Gomes (PI), Henrique Morelli. Hospital Cardiológico Costantini, Curitiba, PR: Costantino R. Costantini (PI), Sérgio G. Tarbine, Marcelo F. Santos, Costantino C. Ortiz, Anici B. de Souza. Hospital Universitário Cajuru PUC - PR, Curitiba, PR: Roberto Pecoits-Filho (PI), Gelson Koppe, Priscila D. Hoffman. Hospital Santa Casa de Misericórdia de Curitiba, Curitiba, PR: José R. Faria Neto (PI), Ricardo Wang, Cristiane Cury. Centro de Diagnose Cardiovascular - Santa Casa de Misericórdia, Curitiba, PR: Newton Stadler (PI), Deborah C. Nercolini, Claudia Zanuzzi. Serviço de Hemodinâmica e Cardiologia Intervencionista do Hospital Evangélico de Curitiba, Curitiba, PR: Ronaldo R. Bueno (PI), Enio E. Guerios (PI), José C. E. Tarastchuk. Hospital Paraná, Maringá, PR: Mário L. Peixoto (PI). Hospital do Coração de Londrina, Londrina, PR: André Labrunie (PI), Pedro B. de Andrade, Marden A. Tebet. Hospital SOS Cardio, Florianópolis, SC: Luiz E. S. Thiago (PI), Luiz C. Giuliano, Fernando G. Aranha, Marcielle Misiak. Instituto de Cardiologia, São José, SC: Luiz E. S. Thiago (PI), Luiz C. Giuliano, Maria H. Antunes, Rosana S. da Conceição. UNISUL - Hospital Socimed, Tubarão, SC: Silvia M. Abreu (PI), Julio C. Preve. Hospital Santa Helena - São Francisco - Cardio Vida, Aparecida de Goiânia, GO: José S. P. Guimarães (PI), David de Araújo Filho. Hospital do Coração do Brasil, Brasília, DF: Edmur C. Araújo (PI), Luciano N. L. de Sousa, 
Alberto G. T. Fonseca. Instituto do Coração Taguatinga, Taguatinga, DF: Paulo A. M. da Motta (PI), Evandro C. V. Osterne, Vicente P. Da Motta, Anna C. G. R. Zimmermann.

\section{References}

I. Hou SH, Bushinsky DA, Wish JB, Cohen JJ, Harrington JT: Hospitalacquired renal insufficiency: a prospective study. Am J Med 1983, 74:243-248.

2. McCullough PA, Wolyn R, Rocher LL, Levin RN, O'Neill WW: Acute renal failure after coronary intervention: incidence, risk factors, and relationship to mortality. Am J Med 1997, 103:368-375.

3. Parfrey PS, Griffiths SM, Barrett BJ, Paul MD, Genge M, Withers J, Farid N, McManamon PJ: Contrast material-induced renal failure in patients with diabetes mellitus, renal insufficiency, or both. A prospective controlled study. N Engl J Med 1989, 320:143-149.

4. Morcos SK, Thomsen HS, Webb JA: Contrast-media-induced nephrotoxicity: a consensus report. Contrast Media Safety Committee, European Society of Urogenital Radiology (ESUR). Eur Radiol 1999, 9:1602-1613.

5. Cigarroa RG, Lange RA, Williams RH, Hillis LD: Dosing of contrast material to prevent contrast nephropathy in patients with renal disease. Am J Med 1989, 86:649-652.

6. Pannu N, Wiebe N, Tonelli M: Prophylaxis strategies for contrast-induced nephropathy. JAMA 2006, 295:2765-2779.

7. McCullough PA, Bertrand ME, Brinker JA, Stacul F: A meta-analysis of the renal safety of isosmolar iodixanol compared with lowosmolar contrast media. J Am Coll Cardiol 2006, 48:692-699.

8. Mueller C, Buerkle G, Buettner HJ, Petersen J, Perruchoud AP, Eriksson $U$, Marsch S, Roskamm H: Prevention of contrast mediaassociated nephropathy: randomized comparison of 2 hydration regimens in 1620 patients undergoing coronary angioplasty. Arch Intern Med 2002, 162:329-336.

9. Merten G], Burgess WP, Gray LV, Holleman JH, Roush TS, Kowalchuk GJ, Bersin RM, Van MA, Simonton CA III, Rittase RA, et al.: Prevention of contrast-induced nephropathy with sodium bicarbonate: a randomized controlled trial. JAMA 2004, 29I:2328-2334.

10. Briguori C, Airoldi F, D'Andrea D, Bonizzoni E, Morici N, Focaccio A, Michev I, Montorfano M, Carlino M, Cosgrave J, et al.: Renal Insufficiency Following Contrast Media Administration Trial (REMEDIAL): a randomized comparison of 3 preventive strategies. Circulation 2007, II 5:121I-1217.

II. Recio-Mayoral A, Chaparro M, Prado B, Cozar R, Mendez I, Banerjee $D$, Kaski JC, Cubero J, Cruz JM: The reno-protective effect of hydration with sodium bicarbonate plus $\mathbf{N}$-acetylcysteine in patients undergoing emergency percutaneous coronary intervention: the RENO Study. J Am Coll Cardiol 2007, 49:1283-1288

12. Brar SS, Shen AY, Jorgensen MB, Kotlewski A, Aharonian VJ, Desai N, Ree M, Shah AI, Burchette RJ: Sodium bicarbonate vs sodium chloride for the prevention of contrast medium-induced nephropathy in patients undergoing coronary angiography: a randomized trial. JAMA 2008, 300:1038-1046.

13. Bagshaw SM, Ghali WA: Acetylcysteine for prevention of contrast-induced nephropathy after intravascular angiography: a systematic review and meta-analysis. BMC Med 2004, 2:38.

14. Bagshaw SM, McAlister FA, Manns BJ, Ghali WA: Acetylcysteine in the prevention of contrast-induced nephropathy: a case study of the pitfalls in the evolution of evidence. Arch Intern Med 2006, 166:161-166.

15. Gonzales DA, Norsworthy KJ, Kern SJ, Banks S, Sieving PC, Star RA, Natanson C, Danner RL: A meta-analysis of $\mathbf{N}$-acetylcysteine in contrast-induced nephrotoxicity: unsupervised clustering to resolve heterogeneity. BMC Med 2007, 5:32.

16. Kelly AM, Dwamena B, Cronin P, Bernstein SJ, Carlos RC: Metaanalysis: effectiveness of drugs for preventing contrastinduced nephropathy. Ann Intern Med 2008, 148:284-294.

17. Briguori C, Manganelli F, Scarpato P, Elia PP, Golia B, Riviezzo G, Lepore S, Librera M, Villari B, Colombo A, et al.: Acetylcysteine and contrast agent-associated nephrotoxicity. I Am Coll Cardiol 2002, 40:298-303.

18. DerSimonian R, Laird N: Meta-analysis in clinical trials. Control Clin Trials 1986, 7:177-188.
19. Dodd S, Dean O, Copolov DL, Malhi GS, Berk M: N-acetylcysteine for antioxidant therapy: pharmacology and clinical utility. Expert Opin Biol Ther 2008, 8: $1955-1962$.

20. Montori VM, Devereaux PJ, Adhikari NK, Burns KE, Eggert CH, Briel M, Lacchetti C, Leung TW, Darling E, Bryant DM, et al.: Randomized trials stopped early for benefit: a systematic review. JAMA 2005, 294:2203-2209.
Publish with Bio Med Central and every scientist can read your work free of charge

"BioMed Central will be the most significant development for disseminating the results of biomedical research in our lifetime. "

Sir Paul Nurse, Cancer Research UK

Your research papers will be:

- available free of charge to the entire biomedical community

- peer reviewed and published immediately upon acceptance

- cited in PubMed and archived on PubMed Central

- yours - you keep the copyright

Submit your manuscript here:

http://www.biomedcentral.com/info/publishing_adv.asp
BiolMedcentral 